\title{
Les vecteurs herpétiques pour le transfert de gènes
}

Les vecteurs dérivés du virus $\mathrm{HSV}$-1, que ce soient les virus recombinants ou les amplicons, sont actuellement employés pour introduire des gènes principalement dans des cellules post-mitotiques de mammifères. Ils sont utilisés pour explorer les connexions et les flux d'information dans les réseaux neuronaux, pour identifier des régions du cerveau permissives à l'expression de certains promoteurs, pour modifier la physiologie cellulaire par induction de la synthèse d'une protéine mutée ou d'une protéine normalement absente dans un type cellulaire donné, et enfin pour complémenter l'absence d'une protéine dans le cas d'une cellule mutée ou carencée par axotomie. L'utilité de ces vecteurs ne se limite pas, d'ailleurs, au système nerveux. Cependant, des progrès importants restent à accomplir dans la compréhension de certains aspects fondamentaux de la pathogénie virale, dans la suppression des effets cytotoxiques de ces vecteurs et dans la maîtrise de la régulation de l'expression du transgène, avant que ces vecteurs ne puissent être utilisés dans le cadre d'une thérapie génique chez l'homme.

\section{Alberto Epstein}

\section{ADRESSE}

A. Epstein : chargé de recherche au Cnrs. UMR 106, Cnrs, centre de génétique moléculaire et cellulaire, université Claude-Bernard, Lyon I, 43, boulevard du 11-Novembre-1918,

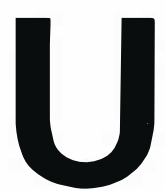

ne des applications les plus spectaculaires du développement récent de la génétique moléculaire consiste en l'utilisation d'un virus comme vecteur pour introduire un gène à l'intérieur d'une cellule. médecine/sciences a publié récemment plusieurs articles illustrant les énormes potentialités de cette approche, non seulement du point de vue de leur éventuelle utilisation en thérapie génique, mais aussi en tant que moyen d'étude du développement, de la physiologie et de la régulation de l'expression génique de l'hôte. Outre les rétrovirus [1] et les adénovirus [2], d'autres vecteurs viraux potentiellement très intéressants (dérivés de papovavirus, herpesvirus, poxvirus, parvovirus) sont actuellement utilisés de manière expérimentale [3]. Nous voulons, dans cet article, faire le point sur les vecteurs dérivés du virus herpès simplex de type 1 (HSV-1) car, à condition de maîtriser leurs aspects négatifs, ces vecteurs vont certainement devenir un outil de choix pour le transfert de séquences d'ADN de grande taille, en premier lieu dans les cellules nerveuses, et probablement dans d'autres types cellulaires post-mitotiques.

Étant donnée la complexité de la structure des virus herpétiques, de la régulation de leur expression et de leurs mécanismes pathogéniques, il nous semble nécessaire d'introduire d'abord quelques éléments essentiels du cycle biologique de ces virus.

\section{L'infection herpétique}

HSV-1, prototype de la sous-famille des virus herpès neurotropes, pénètre dans l'organisme humain générale- 
ment par les muqueuses orales et péri-orales. Là, le virus accomplit quelques cycles réplicatifs, lytiques, donnant lieu à une infection primaire qui guérit au bout de quelques jours. Pendant cette courte période, des particules virales vont pénétrer dans les terminaisons axonales des neurones sensitifs innervant la région infectée, et les capsides vont voyager de façon rétrograde jusqu'aux ganglions trijumeaux. Le virus s'établit de manière latente dans les noyaux des neurones sensitifs de ces ganglions et peut y persister durant toute la vie de l'hôte. Cependant, le virus peut être périodiquement réactivé et redescendre de manière antérograde jusqu'aux muqueuses. De nouveaux cycles pro- ductifs, conduisant à la lyse des cellules épithéliales, provoquent alors une infection secondaire. Dans un organisme immunocompétent, cette récurrence reste temporairement limitée et topologiquement restreinte à la région innervée par les neurones infectés de manière latente $[4,5]$.

Les aspects cellulaires et moléculaires de l'infection productive sont aujourd'hui relativement bien compris. Le programme d'expression et de réplication du génome viral est strictement contrôlé par des régulateurs viraux et cellulaires agissant en trans, et suit un ordre très précis. A l'inverse, notre compréhension du phénomène de la latence est encore très partielle. La figure 1 résume les

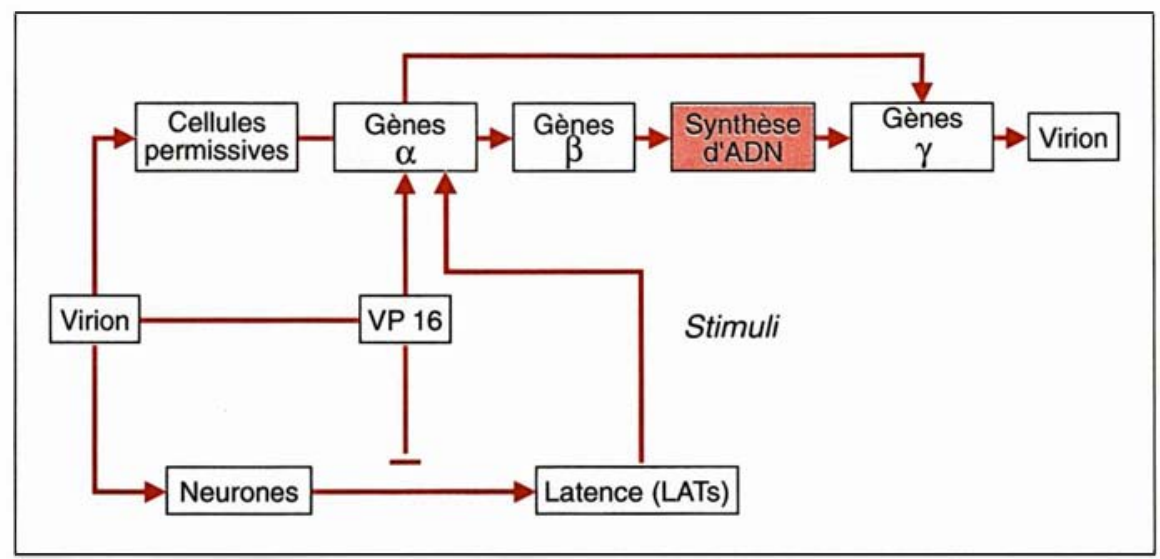

Figure 1. Infection lytique et infection latente. Lorsque le virus infecte des cellules permissives pour la réplication (nerveuses ou non), une protéine structurale du virion appelée VP16 forme un complexe avec au moins deux protéines cellulaires, dont une est le facteur de transcription Oct-1 [6]. L'association avec Oct-1 permet à VP16 d'interagir avec des motifs octamériques existant dans I'ADN viral, en amont des promoteurs des gènes viraux très précoces (ou $\alpha$ ), et d'activer fortement leur transcription [7, 8]. Parmi les cinq gènes $\alpha$, au moins quatre (ICPO, ICP4, ICP22 et ICP27) codent pour des phosphoprotéines trans-régulatrices qui, ensemble ou séparément, régissent l'expression des gènes viraux précoces $(\beta)$ et tardifs $(\gamma)[4,9]$. Parmi les fonctions précoces ( $\beta)$, plusieurs participent au métabolisme des nucléotides (thymidine kinase (TK), ribonucléotide réductase (RDR), dUTPase, DNAase alkalinel, et sept $d^{\prime}$ entre elles participent directement à la réplication de l'ADN viral. Celle-ci est initiée à partir des origines de réplication et s'effectue essentiellement avec des protéines virales [10]. L'ADN nouvellement répliqué sert de matrice pour la synthèse des fonctions tardives $(\gamma)$, dans lesquelles on trouve principalement les protéines de structure du virion (capside, tégument, et glycoprotéines de l'enveloppe). La formation et la libération des particules virales en nombre élevé s'accompagne de la lyse de la cellule hôte [4]. Lorsque le virus pénètre dans certains neurones, l'expression des gènes $\alpha$ n'est pas activée et le virus entre alors dans un état de latence où le génome viral persiste sous forme circulaire et dans lequel, apparemment, seule l'unité de transcription LAT est active. La participation de VP16 à la régulation de cette étape reste pour l'instant hypothétique. De nombreux stimuli agissant sur les neurones peuvent déclencher l'activation des gènes $\alpha$ et donc du cycle lytique (voir texte).

$\mathrm{m} / \mathrm{s} n^{\circ} 9 \mathrm{vol} .8$, novembre 92 aspects moléculaires les plus significatifs des deux types d'infection. La structure du génome viral ainsi que les changements qu'elle subit lors de l'infection d'une cellule permissive pour la réplication sont schématisés sur la figure 2 (p. 904).

\section{Neurovirulence et infection latente}

Lorsque le virus infecte les neurones, centraux ou périphériques, deux issues sont possibles. Il peut établir un cycle réplicatif normal, menant à la lyse de la cellule et à la transmission du virus à d'autres neurones [11], ou bien il peut entrer en latence et persister dans les noyaux cellulaires sous forme de cercles épisomiques de structure chromatinienne [12, 13]. Ces différentes issues sont déterminées, en partie, par le type et l'état transcriptionnel du neurone infecté, par le nombre de virions qui pénètrent dans la cellule et par la virulence de la souche virale employée [14].

Lorsqu'un virus HSV-1 sauvage pénètre dans le cerveau d'un animal, par inoculation périphérique ou intracrânienne, l'infection produit généralement une encéphalite très sévère, souvent létale. L'efficacité du transport trans-synaptique de HSV-1 est telle que ce virus peut être utilisé pour explorer l'organisation du système d'interconnexions qui caractérisent le système nerveux central (SNC) des vertébrés. HSV-1 semble avoir un tropisme particulier pour les aires limbiques, telles que l'hippocampe et l'amygdale [15]. Cependant, la neurovirulence de HSV-1 et l'acheminement du virus au sein du cerveau peuvent varier selon la souche virale et le site d'inoculation. Zymanick et al. [16], par exemple, ont décrit que lorsque la souche McIntyre de HSV-1 est inoculée dans l'aire brachiale du cortex moteur primaire, les particules sont transportées de façon rétrograde jusqu'aux noyaux de neurones situés au niveau du thalamus ventrolatéral. Le virus peut franchir une étape supplémentaire et infecter des neurones du globus pallidus (segment interne) et même des noyaux cérébelleux profonds (dentate et interpositus). A l'inverse, des particules de la souche H129 de HSV-1, 


\section{RÉFÉRENCES}

1. Lehn P. Vecteurs rétroviraux et transfert de gènes dans le tissu hématopoïétique in vivo. médecine/sciences $1990 ; 6: 791-9$.

2. Chasse JF, Levrero $\mathrm{M}$, Kamoun $\mathrm{P}$, Minet M, Briand P, Perricaudet M. L'adénovirus : vecteur de thérapie génique ? médecine/sciences $1989 ; 5: 331-7$.

3. Muzycska N. Viral expression vectors. In : Current Topics in Microbiology and Immunology, vol. 158. Berlin-Heidelberg : Springer-Verlag, 1992.

4. Roizman B, Sears AE. Herpesviruses and their replication. In : Fields $B N$, Knipe DM, eds. Virology, 2nd ed. New York: Raven Press, 1990 : 1795-1842.

5. Stevens JG. Human herpesviruses : a consideration of the latent state. Microbiol Rev 1989 ; 53 : 318-32.

6. McKnight JLC, Kristie TM, Roizman $B$. The binding of the virion protein mediating $\alpha$ gene induction in herpes simplex virus 1 infected cells to its cis site requires cellular proteins. Proc Natl Acad Sci USA 1987 ; $84: 7061-5$.

7. O'Hare P, Goding CR. Herpes simplex virus regulatory elements and the immunoglobulin octamer domain bind a common factor and are both targets for virion transactivation. Cell 1988 ; 52 : 435-45.

8. Kristie 'ГМ, Lebowitz JH, Sharp PA. The octamer binding proteins form multiprotein-DNA complexes with the HSV $\alpha$ TIF regulatory protein. $E M B O J 1989 ; 8$ : 4229-38.

9. Honess RW, Roizman B. Regulation of herpesvirus macromolecular synthesis : sequential transition of polypeptide synthesis requires functional viral polypeptides. Proc Natl Acad Sci USA 1975 ; 72 : 1276-80. 10. Challberg MD, Kelly TJ. Animal virus DNA replication. Annu Rev Biochem 1989 ; 58 : 671.717

11. Ugolini G, Kuypers HG, Strick PL. Transneuronal transfer of herpes virus from peripheral nerves to cortex and brainstem. Science 1989; 243 : 89-91.

12. Mellerick DM, Fraser NW. Physical state of the latent herpes simplex virus genome in a mouse model system : evidence suggesting an episomal state. Virology 1987 ; 158: 265-75.

13. Deshmane SL, Fraser NW. During latency, herpes simplex virus type $1 \mathrm{DNA}$ is associated with nucleosomes in a chromatin structure. J Virol $1989 ; 63$ : 943-7.

14. Breakefield XO, DeLuca NA. Herpes simplex virus for gene delivery to neurons. New Biol 1991; 3: 203-18.

15. Chrisp CE, Sunstrum JC, Averill DR, Levine M, Glorioso J. Characterization of encephalitis in adult mice induced by intracerebral inoculation of herpes simplex virus type 1 (KOS) and comparison with mutants showing decreased virulence. Lab Invest $1989 ; 60: 822-30$.

16. Zemanick MC, Strick PL, Dix RD. Direction of transneuronal transport of herpes simplex virus 1 in the primate motor system is strain-dependent. Proc Natl Acad Sci USA $1991 ; 88: 8048-51$

17. Dobson AT, Margolis TP, Sedarati F, Stevens JG, Feldman LT. A latent, nonpathogenic HSV-1 derived vector stably expresses beta-galactosidase in mouse neurons. Neuron 1990; 5 : 353-60.

\section{A}

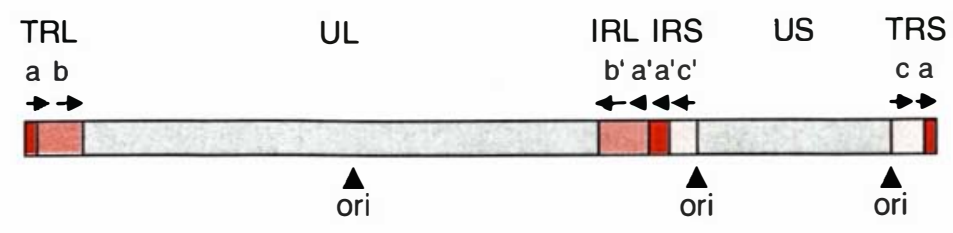

B

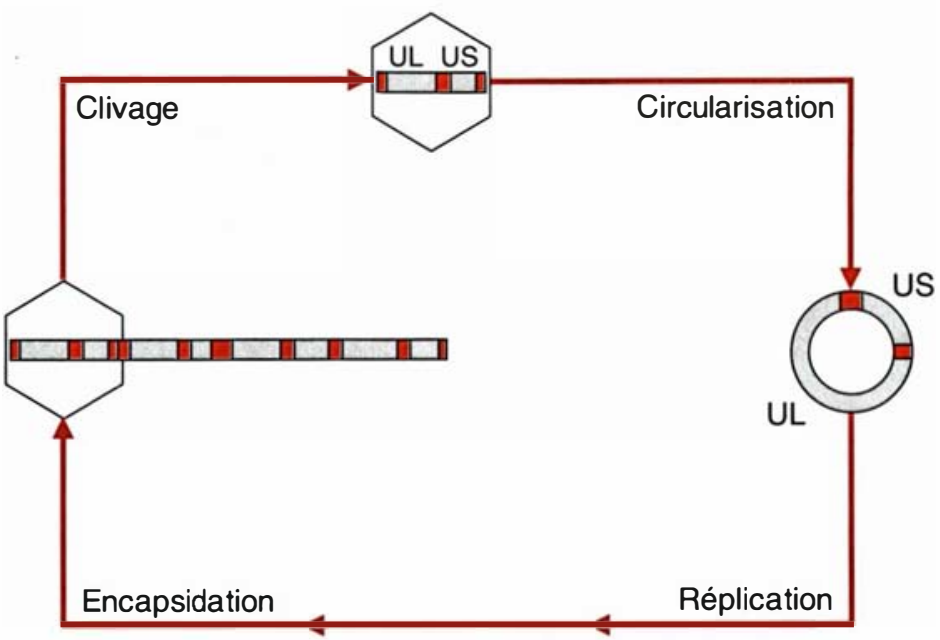

二IL US UL US UL US UL US UL

Figure 2. Structure et cycle du génome viral. (A) Le génome de HSV-1, d'une taille de $153 \mathrm{kpb}$, code pour un minimum de 72 protéines. II possède trois origines de réplication (ori). Purifiée et déprotéinisée, cette molécule est infectieuse. Le génome viral comporte deux régions uniques, appelées $U_{L}$ et $U_{S}$, chacune entourée par des séquences répétées et inversées : les séquences entourant $U_{L} s^{\prime}$ appellent $T R_{L}$ et $I R_{L}$ (ou $a b$ et $b^{\prime} a^{\prime}$ ), et celles entourant $U_{S} s^{\prime} a p p e l l e n t$ IRS et TRS (ou a'c' et ca). Le génome commence et se termine donc par une séquence " a " non inversée, d'environ 400 nucléotides, et cette même séquence se retrouve répétée et inversée à la jonction de IRL et IRS. (B) Le génome de HSV-1 se trouve sous forme linéaire dans les virions, mais il prend une configuration circulaire dès qu'il arrive aux noyaux cellulaires. Quelques heures après commence la réplication : elle se fait vraisemblablement selon le modèle des "cercles roulants" et passe donc par la formation de longues structures concatémériques intermédiaires, où des unités génomiques sont répétées en tandem. Simultanément à la réplication de l'ADN viral a lieu l'expression des fonctions tardives qui permettront l'assemblage des capsides. L'ADN viral concatémérique pénètre alors dans les capsides vides par l'une de ses extrémités, et ce processus continue jusqu'à ce que près de $150 \mathrm{kpb} d^{\prime} A D N$ aient été encapsidés. Un mécanisme de clivage se déclenche alors, qui va couper l'ADN intermédiaire au niveau de la séquence "a " la plus proche. Cette nucléocapside s'entoure ensuite de ses couches externes /tégument et enveloppel avant de quitter le noyau, de traverser le cytoplasme par les membranes du réticulum endoplasmique et l'appareil de Golgi, et d'être relâchée dans le milieu extracellulaire. 
le même site, seront transportées de manière antérograde pour infecter des neurones du putamen et des noyaux du pont et, éventuellement, des neurones du globus pallidus (essentiellement le segment externe) et du cortex cérébelleux (cellules granulaires et cellules de Golgi) [16].

L'infection latente a normalement lieu dans les neurones sensitifs, mais elle peut-être observée aussi dans des neurones moteurs, dans certains neurones du SNC et même dans des tissus non nerveux [17-19]. Lors de la pénétration du virus dans certains neurones, le transactivateur viral VP16 n'active pas la transcription des gènes très précoces, peut-être à cause de la très faible expression d'Oct-1 dans ces cellules [20] (voir légende de la figure 1). Ces neurones pourraient aussi exprimer un facteur qui, en se liant aux séquences de régulation des gènes très précoces, inhiberait l'action de VP16 [21]. Quelle qu'en soit la raison, l'infection latente de $\mathrm{HSV}-1$ est caractérisée par l'absence totale de synthèse de protéines virales. La seule expression virale stable détectée dans des neurones infectés de manière latente correspond à deux ARN nucléaires de 1,3 et $2 \mathrm{~kb}$, non polyadénylés et non coiffés, appelés LAT (latency associated transcripts, transcrits associés à la latence). Ils représentent vraisemblablement des introns stables, dérivés par épissage alternatif d'un transcrit primaire de $8,3 \mathrm{~kb}$. L'ARNm mûr dérivé de ce transcrit primaire n'a pas été détecté dans les neurones $[22,23]$. Le promoteur de l'unité de transcription LAT est plus actif dans les neurones que dans d'autres types cellulaires [24]. Les gènes LAT et ICP0, situés sur les brins opposés de l'ADN, sont partiellement complémentaires, et leurs transcrits peuvent théoriquement s'associer. Le piégeage des transcrits d'ICP0 par l'ARN LAT pourrait être l'une des bases moléculaires du maintien de la latence. Pourtant, des HSV-1 mutés, dans lesquels l'unité de transcription LAT a été délétée, sont tout à fait capables de s'établir et de se maintenir à l'état latent. Seule la réactivation semble partiellement compromise [25]. Le rôle des transcrits LAT dans l'établissement ou le maintien de la latence reste donc controversé.
La réactivation de HSV-1 peut être induite par de nombreux stimuli, d'ordre physique, hormonal ou émotionnel. Le virus peut aussi être réactivé lors de la mise en culture de neurones infectés, surtout lorsque ces cellules sont privées de facteur de croissance des celllules nerveuses (NGF), facteur qui serait nécessaire au maintien de l'état latent [26]. Quel que soit le stimulus initial, la réactivation du virus est certainement due à la transduction d'un signal qui active directement ou indirectement la transcription des gènes très précoces. La mise en culture de neurones induit l'activation de nombreux facteurs de transcription cellulaires, incluant Oct-1 [27].

\section{Le virus $H S V-1$ en tant que vecteur de gènes}

Plusieurs caractéristiques font de HSV-1 un candidat intéressant pour le transfert de gènes: (a) ce virus possède un très long génome, contenant au moins 72 gènes, qui a été complètement séquencé [28-31] et qui est de manipulation relativement aisée. Un nombre important de gènes non essentiels en culture de cellules (près d'une trentaine) peuvent être délétés du génome pour laisser la place, en théorie, à plus de $30 \mathrm{kpb}$ d'ADN exogène [32] ; (b) HSV-1 peut infecter la plupart des types cellulaires de mammifères, indépendamment de leur origine tissulaire [4]. Il peut être produit à de très hauts titres (supérieurs à $10^{9} \mathrm{pfu} / \mathrm{ml}$ ) et être stocké longtemps sans perte de pouvoir infectieux ; (c) contrairement aux rétrovirus, l'expression des herpèsvirus ne nécessite pas d'intégration dans le génome cellulaire. Ils peuvent donc être employés comme vecteurs d'expression extrachromosomiques dans les cellules post-mitotiques ou en état de quiescence, avec peu de risque (comparés aux rétrovirus) de perturber l'expression des gènes cellulaires par mutagenèse insertionnelle ; (d) le neurotropisme naturel de HSV-1, sa capacité à se déplacer dans les neurones de façon antérograde, et rétrograde, et à se transmettre essentiellement de manière trans-synaptique [33], ainsi que son aptitude à entrer en latence dans les cellules nerveuses tout en restant dans un état transcriptionnel actif (unité de transcription LAT), font de lui un vecteur idéal pour le transfert de gènes dans le système nerveux [14].

\section{Types de vecteurs herpétiques}

Il existe deux types de vecteurs HSV-1 : les virus recombinants et les amplicons (plasmides encapsidés). Les virus recombinants véhiculent des séquences d'ADN qui ont été introduites dans le génome viral par recombinaison homologue. Ils constituent des populations virales génétiquement homogènes [34]. La procédure employée pour construire et sélectionner ces virus recombinants est illustrée dans la figure 3, p. 904.

Les amplicons sont des plasmides bactériens qui contiennent une origine de réplication HSV-1 (ori), et un signal de clivage et d'encapsidation des génomes viraux (séquence " a ") [35]. Le transgène d'intérêt est introduit dans ce plasmide par simple manipulation in vitro. L'amplicon est un vecteur défectif qui est amplifié et encapsidé à l'aide d'un virus auxiliaire. Les populations virales résultantes seront donc constituées d'un mélange d'amplicons et de virus auxiliaire (celui-ci pouvant être sauvage, atténué ou défectif) [36]. Ce type de vecteur possède toujours plusieurs copies en tandem du transgène (figure 4, p. 905).

\section{Problèmes et limites liés à I'utilisation de ces vecteurs}

Comme pour tous les vecteurs viraux, nous devons considérer les problèmes liés à l'éventuelle dissémination du vecteur, à sa cytotoxicité, à la régulation de l'expression du transgène (qui doit rester dans des limites physiologiques) et à la stabilité de cette expression. D'autant plus que, à cause de la distribution très ubiquitaire des récepteurs pour HSV-1, le ciblage strict in vivo n'est possible que grâce au contrôle de l'expression du transgène.

Par ailleurs, dans la mesure où la multiplication de HSV-1 entraîne généralement la mort de la cellule infectée, l'expression stable du trans- 


\section{RÉFÉRENCES}

18. Deatly AM, Spivack JG, Lavi E, O'Boyle DR II, Fraser NW. Latent herpes simplex virus type 1 transcripts in peripheral and central nervous system tissues of mice map to similar regions of the viral genome. J Virol 1988 ; 62: 749-56.

19. Stevens JG. Latent characteristics of selected herpesviruses. Adv Cancer Res 1978 ; $26: 227-56$

20. He X, Treacy MN, Simmons DM, Ingraham HA, Swanson LW, Rosenfeld MG Expression of a large family of POU-domain regulatory genes in mammalian brain development. Nature $1989 ; 340$ : 35-42.

21. Kemp LM, Dent CL, Latchman DS Octamer motif mediates transcriptional repression of HSV immediate-early genes and octamer-containing cellular promoters in neuronal cells. Neuron 1990; 4 : 215-22. 22. Stevens JG, Wagner EK, Devi-Rao GB, Cook ML, Feldman LT. RNA complementary to a herpesvirus alpha gene mRNA is prominent in latently infected neurons. Science $1987 ; 235$ : 1056-9.

23. Stevens JG. Herpes simplex virus latency analysed by in situ hybridization Curr Top Microbiol Immunol $1989 ; 143: 1-8$. 24. Batchelor $\mathrm{AH}, \mathrm{O}$ 'Hare P. Regulation and cell-type-specific activity of a promoter located upstream of the latency-associated transcript of herpes simplex virus type 1. J Virol 1990 ; 64 : 3269-79.

25. Leib DA, Bogard CL, Kosz-Vnenchak $M$, et al. A deletion mutant of the latency-associated transcript of herpes simplex virus type 1 reactivates from the latent state with reduced frequency. $J$ Virol 1989 ; $63:$ 2893-2900.

26. Wilcox CL, Johnson EM Jr. Characterization of nerve growth factor-dependent herpes simplex virus latency in neurons in vitro. J Virol 1988; 62 : 393-9.

27. Valyi-Nagy T, Deshmane S, Dillner A Fraser NW. Induction of cellular transcription factors in trigeminal ganglia of mice by corneal scarification, herpes simplex virus type 1 infection and explantation of trigeminal ganglia. J Virol 1991; 65: 4142-52. 28. McGeoch DJ, Dolan A, Donald S Rixon FJ. Sequence determination and genetic content of the short unique region in the genome of herpes simplex virus type 1. J Mol Biol 1985; 181: 1-13.

29. McGeoch DJ, Dolan A, Donald S, Brauer DHK. Complete DNA sequence of the short repeat region in the genome of herpes virus type 1. NAR 1986; 4: 1727-45.

30. McGeoch DJ, Dalrymple MA, Davison AJ, et al. The complete DNA sequence of the long unique region in the genome of herpes simplex virus type 1.J Gen Virol $1988 ; 69: 1531-74$

31. Perry LJ, McGeoch DJ. The DNA sequences of the long repeat region and adjoining parts of the long unique region in the genome of herpes simplex virus type 1. J Gen Virol 1988; $69: 2831-46$

32. Longnecker R, Roizman B, Meignier B. Herpes simplex viruses as vectors : properties of a prototype vaccine strain suitable for use as a vector. In : Gluzman Y, Hughes SH, eds. Viral Vectors. Cold Spring Harbor, NY : CSHL Press, $1988: 68$.

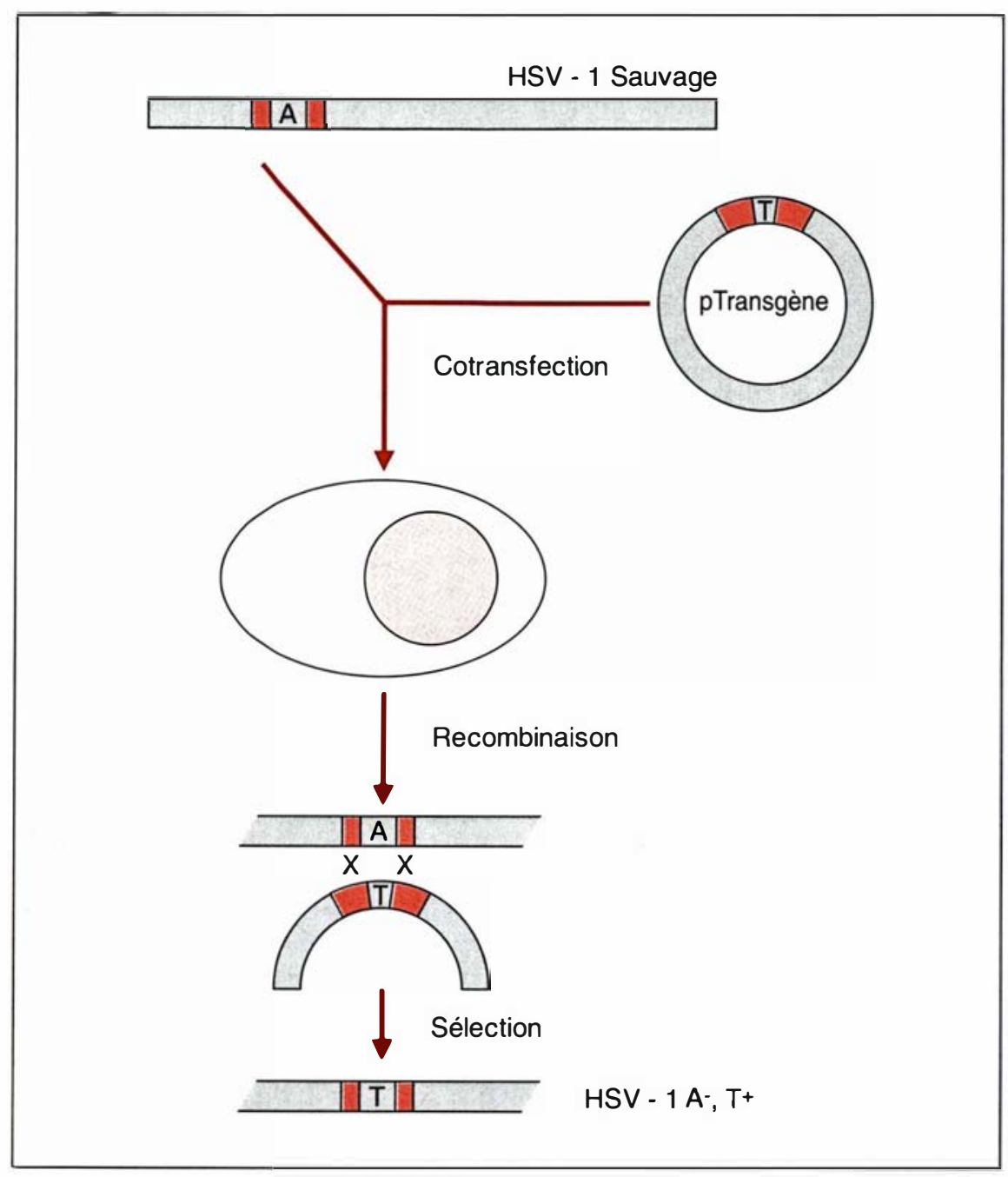

Figure 3. Construction et sélection d'un vecteur recombinant. Pour construire ces vecteurs, des cellules sont co-transfectées avec de l'ADN viral génomique, plus un plasmide contenant le transgène $T$, entouré de séquences virales nécessaires pour que la recombinaison homologue ait lieu (au moins 600 nucléotides de chaque côté). Celle-ci s'effectue lors de la synthèse d'ADN viral, par l'appareil de réplication viral qui est fortement recombinogène. La sélection des virus recombinants peut se faire en faisant appel au phénotype résultant de la délétion du gène viral $\mathbf{A}$ : si le transgène a été introduit dans le locus de la thymidine kinase (TK), on sélectionne des virus TK- à l'aide de l'acyclovir ; s'il a été introduit dans le locus d'une glycoprotéine non essentielle, le recombinant sera sélectionné par utilisation des anticorps neutralisants monospécifiques (les recombinants échappent à la neutralisation). Alternativement, les recombinants peuvent être sélectionnés grâce aux propriétés apportées par le transgène $\boldsymbol{T}$ : pour certains types d'expériences, on peut introduire dans le génome viral des marqueurs tels que le gène de la $\beta$-galactosidase, auquel cas les recombinants seront identifiés au moyen de méthodes couramment employées pour la détection de cette protéine, sans fixation des cellules infectées. De manière plus générale, on peut aussi détecter les recombinants par hybridation moléculaire en utilisant le transgène comme sonde marquée. Lorsque le transgène est introduit à la place d'un gène viral essentiel, il est indispensable de construire au préalable des cellules transcomplémentant l'activité délétée. 
gène ne peut être obtenue qu'en éliminant le potentiel de réplication du vecteur. Puisque normalement HSV-1 ne s'intègre pas dans l'ADN cellulaire, un vecteur rendu défectif sera donc progressivement dilué dans des cellules capables de proliférer. Cela limite, à l'heure actuelle, l'utilisation de ces vecteurs défectifs principalement aux cellules postmitotiques ou en quiescence, tout au moins dans les cas où une expression durable du transgène est requise.

Tel que nous l'avons déjà dit, le cycle biologique de HSV-1 ne passe pas par l'intégration du génome viral dans le génome cellulaire. Cependant, des séquences d'ADN viral peuvent parfois s'intégrer dans des cellules nerveuses ainsi que dans d'autres cellules qui, pour des raisons diverses, échappent à la lyse [37]. Bien que, à notre connaissance, aucun rapport faisant état d'une atteinte des cellules germinales par HSV-1 n'ait été publié, cette possibilité doit susciter, en cas d'utilisation des vecteurs herpétiques chez l'homme, les mêmes considérations d'éthique que lors de l'utilisation de tout autre vecteur viral.

\section{Pathogénicité et toxicité des vecteurs}

Le virus HSV-1 peut infecter et se disséminer dans plusieurs tissus, surtout dans un organisme où les défenses immunitaires sont atteintes. Il est pathogène vis-à-vis des cellules infectées, tant à cause de l'expression des gènes viraux, que de l'inhibition de l'expression des gènes cellulaires [4]. Il est théoriquement possible de résoudre ces problèmes en manipulant le génome viral, afin de supprimer l'expression de la plupart des déterminants génétiques responsables de la pathogénicité et de la cytotoxicité virale. Ainsi, un certain nombre de gènes viraux ont été indépendamment mutés et les phénotypes des virus mutants correspondants ont été étudiés in vivo et in vitro, dans des cellules non nerveuses et nerveuses, y compris dans des neurones in situ. Tel que l'illustre la figure 5, ces mutants peuvent être classés en trois catégories.

- Les virus défectifs absolus. La délétion du gène $\alpha I C P 4$, le principal régula$\mathrm{m} / \mathrm{s} n^{\circ} 9$ vol. 8, novembre 92 teur en trans du virus, bloque le cycle viral dans sa phase très précoce et rend le virus défectif dans tous les types cellulaires (sauf dans des cellules complémentant en trans la fonction délétée) [38]. Ces mutants ne peuvent donc atteindre le système nerveux que par inoculation directe. Ils sont virtuellement non pathogènes car l'infection reste limitée aux seules cellules ayant été en contact avec l'inoculum initial [39]. Ces virus peuvent entrer en latence dans les cellules nerveuses (le promoteur LAT reste actif), mais, en cas de réactivation, seules les fonctions très précoces

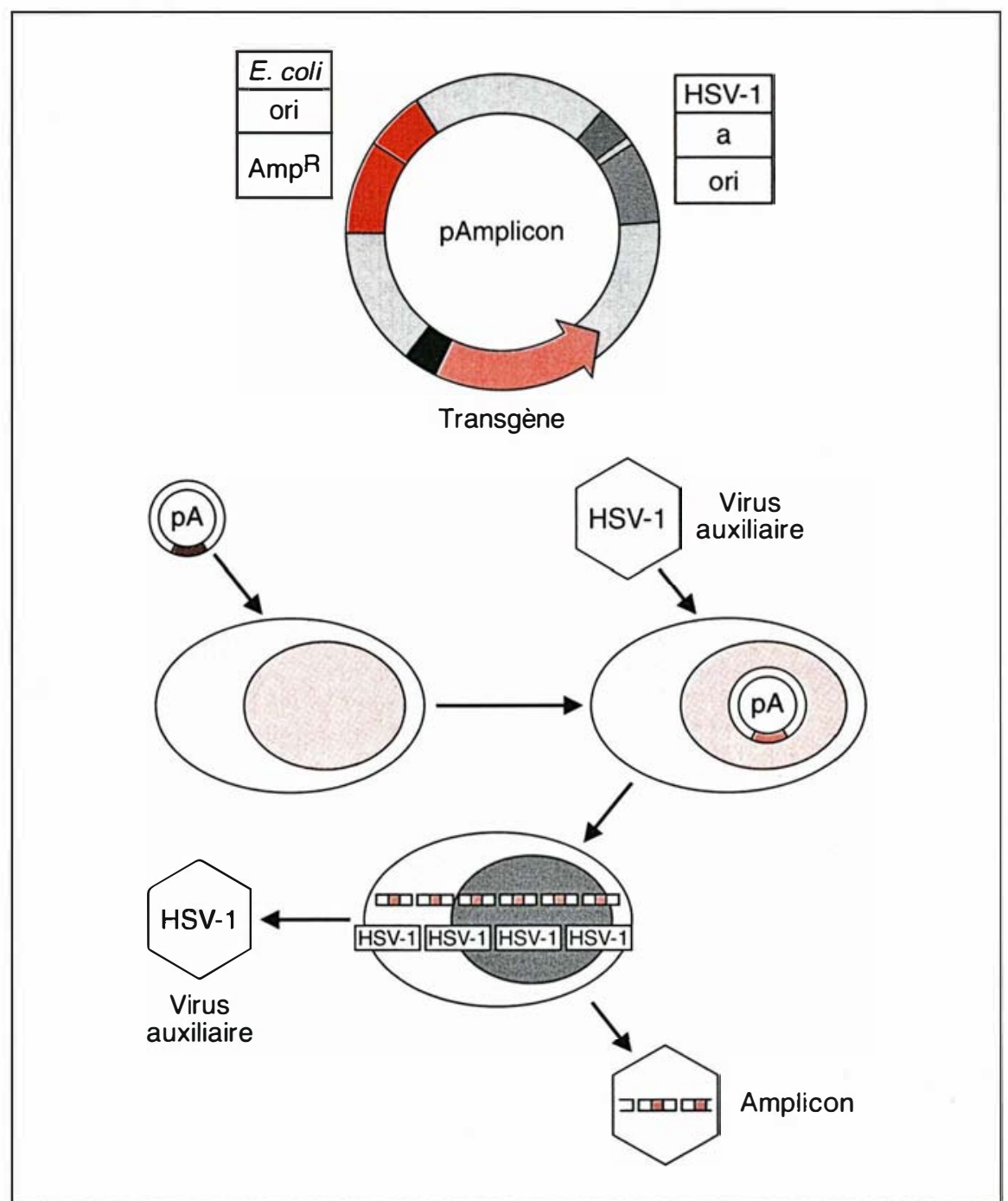

Figure 4. Construction et production d'un vecteur amplicon. Un amplicon est une molécule d'ADN circulaire possédant trois types d'éléments génétiques : (a) une origine de réplication (colE1) et un gène de sélection permettant la propagation de l'ADN en tant que plasmide chez $\mathrm{E}$. coli ; (b) une origine de réplication et une séquence de clivage et d'encapsidation (" a ") herpétiques et (c) le transgène. L'introduction par transfection de ces plasmides recombinants dans des cellules de mammifère, suivie de l'infection avec un HSV-1 auxiliaire, permet la réplication et l'encapsidation du plasmide sous la forme d'un concatémère de taille "herpétique ", c'est-à-dire autour de $150 \mathrm{kpb}$. Autrement dit, le nombre de répétitions en tandem de l'amplicon dépend de la taille du plasmide original (par exemple, un plasmide de $15 \mathrm{kpb}$ sera encapsidé sous la forme de 10 répétitions en tandem). Les populations virales résultantes seront constituées d'un mélange d'amplicons et de virus auxiliaire. Le virus auxiliaire peut être compétent, atténué ou défectif lon utilise alors une lignée cellulaire transcomplémentant la fonction manquantel, mais le vecteur amplicon en tant que tel est évidemment toujours défectif. 


\section{RÉFÉRENCES}

33. Kuypers HG, Ugolini G. Viruses as transneuronal tracers. Trends Neurosci 1990 ; $13: 71-5$.

34. Roizman B, Jenkins FJ. Genetic engineering of novel genomes of large DNA viruses. Science 1985 ; 229 : 1208-14.

35. Spaete RR, Frenkel N. The herpes simplex virus amplicon : analyses of cis-acting replication functions. Proc Natl Acad Sci USA 1985 ; 82 : 694-8.

36. Geller AI, Breakefield XO. A defective HSV-1 vector expresses $E$. coli betagalactosidase in cultured rat peripheral neurons. Science $1988 ; 241$ : 1667-9.

37. Rock DL, Fraser NW. Detection of HSV-1 genome in central nervous system of latently infected mice. Nature 1983 ; 302 : 523-5.

38. DeLuca NA, McCarthy A, Schaffer PA. Isolation and characterization of deletion mutants of herpes simplex virus type 1 in the gene encoding immediate-early regulatory protein ICP4. J Virol $1985 ; 56$ : 558-70.

39. Chiocca EA, Choi BB, Cai W, et al. Transfer and expression of the Lac $Z$ gene in rat brain neurons mediated by herpes simplex mutants. New Biol 1990 ; 2 : 739-46. 40. Johnson PA, Miyanohara A, Levine F, Cahill T, Friedmann T. Cytotoxicity of a replication defective mutant of herpes simplex virus type $1 . J$ Virol $1992 ; 66$ : 2952-65.

41. Coen DM, Kosz-Vnenchak M, Jacobson JG, et al. Thymidine kinase-negative herpes simplex virus mutants establish latency in trigeminal ganglia but do not reactivate. Proc Natl Acad Sci USA 1989; 86 : 4736-40

42. Huang $Q$, Vonsattel JP, Schaffer PA, Martuza RL, Breakefield XÓ, DiFiglia M. Introduction of a foreign gene ( $E$. coli LacZ) into rat neostriatal neurones using herpes simplex virus mutants : a light and electron microscopy study. Exp Neurol 1992 (sous presse).

43. Martuza RL, Malick A, Markert JM, Ruffner KL, Coen DM. Experimental therapy of human glioma by means of a genetically engineered virus mutant. Science 1991; 252: 854-5.

44. Thompson RL, Wagner EK, Stevens JG. Physical location of a herpes simplex virus type 1 function(s) specifically involved with a 10 million-fold increase in HSV neurovirulence. Virology 1983; 131 : 180-92.

45. Chou J, Kern ER, Whitley RJ, Roizman B. Mapping of herpes simplex virus 1 neurovirulence to gamma 34.5 , a gene nonessential for growth in culture. Science $1990 ; 250$ : 1262-6.

46. Fink DJ, Sternberg LR, Weber PC, Mata M, Goins WF, Glorioso JC. In vivo expression of $\beta$-galactosidase in hippocampal neurons by HSV-mediated gene transfer. Hum Gene Ther 1992 ; 3: 12-9.

47. Cai W, Schaffer PA. Herpes simplex virus ICP0 plays a critical role in the de novo synthesis of infectious virus following transfection of viral DNA. J Virol 1989 ; 63 : autres que ICP4 seront exprimées. L'expression de ces fonctions très précoces, dans des cellules nerveuses ou non, suffit à provoquer une toxicité cellulaire résiduelle [40]. Des délétions supplémentaires de ces gènes doivent donc être réalisées, avant de songer à l'introduction de ces vecteurs chez l'homme. La production d'un vecteur comportant des délétions multiples est également importante pour réduire, autant que possible, les risques de production, par recombinaison homologue, d'un vecteur compétent. D'autres mutants défectifs absolus ont été construits par délétion d'autres fonctions essentielles, très précoces ou précoces [14]. Ces mutants, bien que peu pathogènes pour l'organisme, sont relativement plus toxiques pour les cellules infectées que ceux délétés du gène ICP4 - Les virus défectifs conditionnels. Les virus mutés dans le gène de la TK ou de la RDR, par exemple, sont défectifs uniquement dans des cellules non réplicatives, comme les neurones, car dans ces cellules, les faibles taux de déoxynucléotidetriphosphates limitent sévèrement la réplication de l'ADN viral [41]. Ces virus se multiplient cependant dans les cellules capables de proliférer, et peuvent donc atteindre des neurones périphériques à partir d'une infection cutanée. Ils peuvent s'établir normalement en latence, mais, en cas de réactivation, l'infection restera bloquée dans sa phase précoce car l'expression des fonctions tardives dépend absolument de la réplication du génome viral [41]. Ces mutants ne peuvent donc pas se transmettre d'un neurone à l'autre de manière efficace. Bien que l'expression résiduelle des fonctions précoces s'accompagne d'une cytotoxicité pour les neurones infectés, ces mutants sont nettement moins pathogènes que les virus sauvages et, après inoculation directe dans le système nerveux central, les animaux survivent généralement à l'infection [39, 42]. Cependant, il ne faut pas oublier que certaines cellules du système nerveux central, telles que les cellules gliales, épendymales ou endothéliales, peuvent être permissives pour ces mutants et contribuer à une dissémination de l'infection. Dans ce contexte, des travaux récents illustrent un autre développement potentiel des vecteurs défectifs conditionnels: le groupe de R. Martuza a utilisé un virus $\mathrm{TK}^{-}$pour traiter des glioblastomes humains, implantés dans le cerveau de souris nude. L'inoculation intranéoplasique du virus défectif produit un arrêt de la croissance des tumeurs, et s'accompagne d'une augmentation significative du temps de survie des animaux, par rapport aux témoins non infectés, sans introduire de complications apparentes dues à l'infection [43].

Enfin, et pour revenir à notre sujet, il existe aussi d'autres gènes, dont l'inactivation donne lieu à une diminution sévère et spécifique au niveau de la neurovirulence (près de 100000 fois moins pour le gène ү34.5), mais dont les mécanismes d'action, bien que différents des cas déjà mentionnés, ne sont pas encore suffisamment établis [44, 45].

- Les virus atténués. Les virus atténués produisent généralement moins de particules infectieuses dans les cellules permissives et ils ont une plus grande tendance à s'établir et à rester en latence dans les neurones que les virus sauvages. Ces mutants sont intéressants car, contrairement aux autres, ils peuvent atteindre le SNC à partir d'une infection périphérique et se transmettre trans-synaptiquement aux neurones voisins, produisant une "vague " infectieuse limitée, avant d'entrer éventuellement en latence [39]. Davantage de neurones seront ainsi infectés par inoculation intracrânienne avec un virus atténué, qu'avec un vecteur défectif absolu. Néanmoins, la faible production de particules infectieuses et leur forte tendance à entrer en latence rendent ces virus relativement peu neuropathogènes. Après inoculation directe d'un virus atténué dans le cerveau, les animaux survivent généralement à l'infection (les doses létales moyennes par inoculation intracrânienne directe varient avec chaque mutant spécifique, mais elles peuvent être supérieures de plus de 1000 fois à celles des virus parentaux sauvages) $[39,46]$. Parmi les gènes dont la délétion peut donner ce type d'atténuation, on peut citer le gène $\alpha I C P O$ [47], le gène VP16 [48] et le gène US3 (codant pour une protéine kinase) [46].

Finalement, le génome viral code 
pour une protéine de structure du virion, appelée VHS (virus host shutoff), qui est responsable de l'arrêt précoce de la synthèse de macromolécules cellulaires [49]. Ce gène est un candidat supplémentaire à la délétion dans tous les cas de figure, mais aucune étude de toxicité comparée avec de tels mutants n'a été publiée. Loin de constituer un obstacle, la complexité génétique de HSV-1 permet donc de construire le type de mutant le plus apte à l'obtention d'un but précis, et rend ce système très souple, par rapport à d'autres systèmes de vecteurs viraux. Certains programmes de recherche fondamentale peuvent nécessiter des vecteurs capables de se multiplier sur un ou plusieurs types cellulaires et de se transmettre aux cellules voisines. Pour des protocoles de thérapie génique, à l'inverse, les vecteurs défectifs absolus paraissent, à l'heure actuelle, les plus indiqués. Bien que le problème de la cytotoxicité résiduelle de ces mutants ne soit pas encore complètement résolu, ils est vraisemblable qu'il le sera dans les années à venir.

\section{Régulation de l'expression du transgène}

L'expression du transgène véhiculé par un vecteur herpétique dépendra principalement de sa place à l'intérieur du génome viral, du choix des séquences régulatrices et du type cellulaire infecté. Évidemment, la stabilité de l'expression du transgène augmentera avec la diminution de la toxicité cellulaire. Des vecteurs recombinants ou des amplicons ont été utilisés in vitro et in vivo pour permettre l'expression de protéines dans des cellules nerveuses ou non nerveuses. Nous nous limiterons à présenter ici quelques exemples paradigmatiques.

Dans une série de travaux, le groupe de A. Geller a utilisé des vecteurs amplicons, construits à l'aide d'un virus auxiliaire défectif (délétion d'ICP4), pour délivrer différents gènes (LacZ, adénylate cyclase, parvalbumine, protéine kinase II) à l'intérieur de cellules non nerveuses ou nerveuses (neurones du cortex, de l'hippocampe et du striatum) in vitro. Ces travaux ont montré qu'une expression forte et $\mathrm{m} / \mathrm{s} n^{\circ} 9 \mathrm{vol} .8$, novembre 92 "stable" (au moins deux semaines) peut être obtenue à partir de promoteurs des gènes herpétiques très précoces, ou de promoteurs neurospécifiques des gènes codant pour des protéines neurofilamentaires [36, 50-53]. Récemment, le même groupe a commencé à utiliser ces vecteurs amplicons in vivo, chez le rat adulte. Ils ont ainsi introduit le gène codant pour le NGF, sous le contrôle d'un promo- teur viral très précoce, à l'intérieur d'un ganglion cervical supérieur. L'inoculation de ce vecteur induit l'expression de NGF pendant au moins 14 jours et empêche la diminution du taux de tyrosine hydroxylase, qui suit normalement l'interruption de l'apport en NGF par axotomie des neurones du ganglion [54]. En ce qui concerne les virus recombinants, plusieurs groupes ont mon-

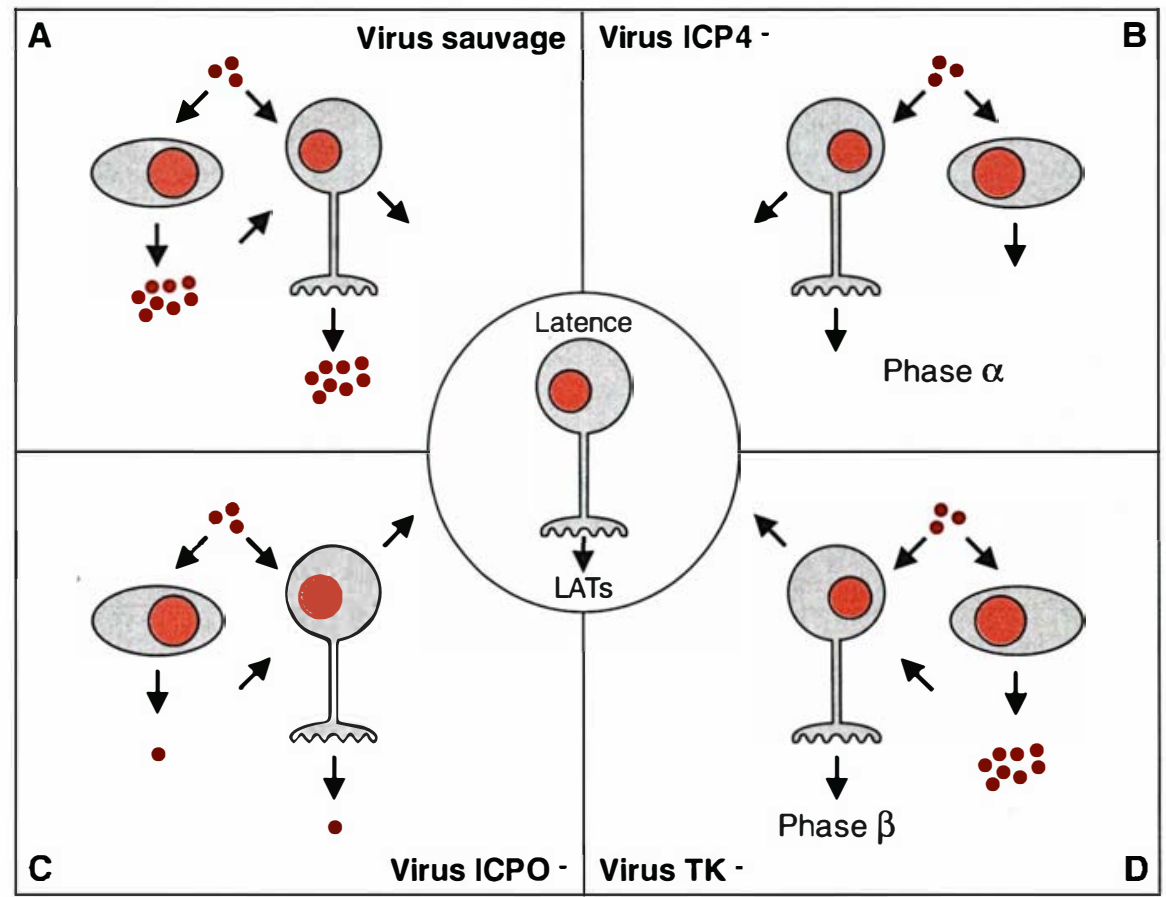

Figure 5. Quatre modèles d'infection virale. (A) Lorsque l'on utilise un HSV-1 sauvage, l'infection d'une cellule permissive pour la réplication se traduit généralement par la mort cellulaire et par la production d'une nouvelle génération de particules infectieuses. Les cellules nerveuses peuvent être infectées par inoculation directe ou par du virus produit par d'autres cellules permissives. L'infection d'un neurone peut aboutir, soit à l'établissement d'un cycle productif, soit à l'établissement de la latence, où seule l'unité de transcription LAT est active. (B) Lorsque le virus est défectif pour une fonction essentielle, par exemple la fonction $\alpha$ ICP4, il ne peut se multiplier que dans des cellules spécialement "construites" pour transcomplémenter la fonction manquante (virus défectif absolu). Dans d'autres cellules, seules les autres fonctions $\alpha$ seront exprimées. Ces virus ne peuvent atteindre les cellules nerveuses que par inoculation directe. Ils peuvent néanmoins $s^{\prime} y$ établir normalement en latence. (C) Un virus atténué, par exemple par délétion de la fonction non essentielle $\alpha$ ICPO, peut en général se multiplier dans les mêmes types cellulaires qu'un virus sauvage, mais en produisant beaucoup moins de particules infectieuses. Dans la mesure où ICPO est un régulateur positif en trans de l'expression des autres fonctions $\alpha$, son absence se traduit par une faible expression $\alpha$ et donc une tendance accrue à entrer ou à rester en latence. (D) Finalement, un virus muté, par exemple, dans le gène de la TK peut se multiplier tout à fait normalement dans des cellules en prolifération (même au sein du système nerveux central), mais il ne se multiplie pas dans les cellules post-mitotiques, telles que les neurones (virus défectif conditionnel). Ces virus peuvent entrer normalement en latence dans les cellules nerveuses, mais lors de la réactivation, ou bien lorsque l'infection n'entre pas en latence, le cycle viral reste bloqué au niveau de la phase précoce de réplication de I'ADN viral. 


\section{RÉFÉRENCES}

48. Ace CI, McKee TA, Ryan JM, Cameron JM, Preston CM. Construction and characterization of a herpes simplex virus type 1 mutant unable to transinduce immediate-early gene expression. $J$ Virol 1989 ; 63 : 2260-9.

49. Kwong AD, Frenkel N. The herpes simplex virus virion host shutoff function. $J$ Virol 1989 ; 63 : 4834-9.

50. Geller AI, Freese A. Infection of cultured central nervous system neurons with a defective herpes simplex virus 1 vector results in stable expression of Escherichia coli beta-galactosidase. Proc Natl Acad Sci USA $1990 ; 87: 1149-53$.

51. Geller AI, Freese A, Neve K, Du ring $M J$, Neve $R$. Stable modification of rat sympathetic neuron physiology and neurotransmitter release by expression of adenylate cyclase from a HSV -1 vector. Soc Neurosci Abstr 1990 ; 16 : 216-25.

52. Freese A, Geller A. Infection of cultu red striatal neurons with a defective HSV-1 vector : implications for gene therapy. $N A R$ $1991 ; 25$ : 7219-23.

53. Boothman DA, Geller AI, Pardee AB. Expression of the $E$. coli $L a c Z$ gene from a defective $\mathrm{HSV}-1$ vector in various human normal, cancer-prone and tumor cells. FEBS Lett 1989 ; 20 : 159-62.

54. Federoff HJ, Geschwind MD, Gel ler AI, Kessler JA. Expression of nerve growth factor from a defective herpes simplex virus 1 vector prevents effects of axotomy on sympathetic ganglia. Proc Natl Acad Sci USA 1992 ; 89 : 1636-40.

55. Smiley JR, Smibert C, Everett RD. Expression of a cellular gene cloned in herpes simplex virus : rabbit beta-globin is regulated as an early viral gene in infected fibroblasts. J Virol 1987; 61 : 2368-77.

56. Ho DY, Mocarsky ES. Beta-galactosidase as a marker in the peripheral and neural tissues of the herpes simplex virusinfected mouse. Virology $1988 ; 167: 279-83$

57. Ho DY, Mocarsky ES. Herpes simplex virus latent RNA (LAT) is not required for latent infection in the mousc. Proc Natl Acad Sci USA 1989 ; 86 : 7596-600.

58. Dobson AT, Sederati F, Devi-Rao G, et al. Identification of the latency-associated transcript promoter by expression of rabbit beta-globin mRNA in mouse sensory nerve ganglia latently infected with a recombinan herpes simplex virus. J Virol 1989; 63 : 3844-51.

59. Palella TD, Hidaka Y, Silverman LJ, Levine M, Glorioso J, Kelley WN. Expres sion of human HPRT mRNA in brains of mice infected with a recombinant herpes simplex virus 1 vector. Gene $1989 ; 80$ : 137-44.

60. Marangos PJ, Schmechel DE. Neuron specific enolase, a clinically useful marker for neurons and neuroendocrine cells. Ann Rev Neurosci 1987 ; 60 : 269-95.

61. Miyanohara A, Johnson PA, Elam RL, et al. Direct gene transfer to the liver with herpes simplex virus type 1 vectors : transient production of physiologically relevant levels of circulating factor IX. New Biol $1992 ; 4$ : 238-46. tré que ces vecteurs (compétents, défectifs ou atténués) peuvent être utilisés in vitro pour introduire des gènes (LacZ, $\beta$-globine, APRT, HPRT', antigène de surface du virus de l'hépatite $B$, ovalbumine...) dans des cellules nerveuses ou non [14]. Ces gènes ont été introduits dans différents loci du génome viral (ICP0, ICP4, UL52, TK, gC, LAT), et sous le contrôle de différents promoteurs herpétiques (très précoces, précoces, tardifs ou LAT) ou non herpétiques, tels que le LTR du virus de Moloney (MoMLV), le promoteur très précoce $\mathrm{du}$ virus cytomégalique humain (HCMV), le promoteur tardif du virus SV40, ceux du gène APRT ou de la $\beta$-globine de lapin [14]. D'une manière générale, tous ces promoteurs s'expriment in vitro de manière forte et non spécifique. Le promoteur de la $\beta$-globine incorporé dans le vecteur viral est actif même dans les cellules VERO, dans lesquelles le gène de la $\beta$-globine endogène n'est pas exprimé [55]. Dans ce cas, le transgène est transcrit avec la même cinétique qu'un gène viral précoce. Les promoteurs viraux de type précoce ne comprennent que quelques séquences de régulation très ubiquitaires (TATA, SP1 et CAATT boxes), et il paraît très probable que tout promoteur cellulaire, dépourvu des séquences de régulation vraiment spécifiques de tissu, se comporte comme un gène précoce dans le contexte du génome viral.

Des résultats essentiellement similaires ont été observés in vivo. Ainsi, Ho et Mocarsky [56] ont obtenu une expression transitoire de la $\beta$ galactosidase, placée sous le contrôle des promoteurs herpétiques ICP4 ou $\mathrm{TK}$, dans des neurones sensitifs de la souris, après inoculation d'un virus compétent dans des sites périphériques (cornée). La $\beta$-galactosidase ou la $\beta$-globine, sous le contrôle du promoteur viral neuro-actif LAT, sont exprimées de manière relativement stable ( 4 semaines) dans les neurones sensitifs des ganglions trijumeaux, infectés de manière latente avec un virus compétent [57, 58]. Dobson et al. [17], en utilisant un virus défectif absolu (délétion d'ICP4), ont observé une expression de la $\beta$-galactosidase, sous le contrôle du promoteur LTR du virus MoMLV, pendant au moins six semaines, dans des neurones sensitifs de la souris. Ils ont observé aussi une expression stable du transgène dans les neurones moteurs du noyau hypoglosse.

Palella et al. [59] ont construit un vecteur recombinant dans lequel la phase codante du gène HPRT humain a été placé dans le locus et sous le contrôle du promoteur de la thymidine kinase virale. L'introduction du virus recombinant dans le cerveau de rat, par inoculation intracrânienne directe dans le ventricule latéral, a permis d'observer une expression transitoire de l'ARNm du transgène. Cette expérience est intéressante car la déficience complète de l'activité HPRT est associée à une maladie neurologique sévère, le syndrome de Lesch-Nyhan.

L'utilisation de promoteurs spécifiques de tissu peut permettre in vivo une expression plus physiologique. Ainsi, dans un travail très récent, le groupe de X. Breakefield (communication personnelle) a étudié l'expression de $\operatorname{Lac} Z$, sous le contrôle soit du LTR du MoMLV, soit du promoteur de l'énolase neuro-spécifique (NSE), dans des cerveaux de rat adulte après inoculation stéréotaxique dans le caudé et le putamen, d'un vecteur HSV-1 déficient en activité TK. Trois jours après inoculation du vecteur, une expression forte de $L a c Z$, sous contrôle du promoteur LTR, a été observée essentiellement au niveau des neurones du striatum. A l'inverse, au jour 17, elle est détectée principalement au niveau de cellules non neuronales, tandis qu'aucune expression n'est décelée 28 jours après l'inoculation. Cela suggère soit que ce vecteur est lytique dans cette région du cerveau, soit que l'expression à partir du promoteur LTR a été soumise à une régulation négative. Avec le promoteur NSE, l'expression est soumise à un contrôle plus subtil : le marquage des neurones est plus faible et disparaît plus rapidement qu'avec le promoteur LTR, lorsque le vecteur est inoculé dans le caudé et le putamen, mais il reste intense même 30 jours après l'infection, dans des cellules neuronales légèrement éloignées du site d'inoculation, lorsqu'il est introduit directement dans le cortex. Cette expression sélective du transgène est proba- 
blement en relation avec la forte activité du promoteur NSE observée dans les cellules pyramidales du cortex [60].

Finalement, et en dehors du système nerveux, Miyanohara et al. [61] ont utilisé un vecteur recombinant défectif (délétion d'ICP4) pour introduire le gène codant pour le facteur IX canin, sous le contrôle du promoteur très précoce du virus HCMV, dans des hépatocytes de souris in vivo. Le virus a été introduit dans le foie de manière directe ou via la veine porte. Dans les deux cas, de très hauts niveaux de la protéine $\mathrm{cF}$-IX ont été observés dans la circulation. Bien que l'expression du transgène n'ait été que transitoire, le vecteur a pu être récupéré, par surinfection avec un HSV-1 compétent, deux mois après l'inoculation, ce qui démontre que le virus défectif peut persister dans les hépatocytes dans un état similaire à celui de la latence, et que le transgène a été soumis à une régulation négative. La substitution du promoteur HCMV par celui de l'unité de transcription virale LAT s'est traduit par une expression quantitativement plus réduite, mais plus prolongée du transgène (plus de 30 jours).

La conclusion générale qui se dégage de l'ensemble de ces études est qu'il est possible d'obtenir une expression forte et transitoire du transgène, tant in vitro qu'in vivo, en utilisant plusieurs types de séquences de régulation. Cependant, une extinction tardive de l'expression du transgène a été souvent observée. Il est certain que ce phénomène peut être en partie expliqué par la mort des cellules infectées, mais, dans d'autres cas, lorsque le génome viral persiste sous une forme extrachromosomique, éventuellement récupérable par surinfection, il est vraisemblable qu'il s'agisse d'une vraie régulation négative de l'expression [61]. Dans d'autres cas, comme nous l'avons vu, des promoteurs censés être spécifiques d'un tissu peuvent induire, lorsqu'ils sont placés dans le contexte du génome viral, une expression ectopique du transgène [55]. Ces exemples montrent bien que l'expression d'un gène à partir d'un chromosome cellulaire ou à partir d'un élément génétique extrachromosomique ne suit pas nécessairement les mêmes règles, et que des progrès importants restent encore à réaliser dans le domaine de la régulation temporale et spatiale de l'expression du gène véhiculé. Il est possible que les deux types de problèmes puissent être résolus par l'introduction de séquences de régulation plus aptes en amont du transgène, possédant par exemple des éléments de régulation négatifs ou, au contraire, des éléments empêchant les nucléosomes de masquer le promoteur. Pour certains programmes de recherche, surtout ceux liés à l'éventuelle utilisation des vecteurs herpétiques en thérapie génique, il sera impératif de résoudre ces questions. A l'heure actuelle, seul le promoteur de l'unité de transcription LAT permet une expression en même temps stable et spécifique, au moins dans les cellules nerveuses.

\section{Conclusion}

Les vecteurs herpétiques commencent à être utilisés avec beaucoup de réussite dans différents programmes de recherche fondamentale concernant essentiellement, mais pas seulement, le système nerveux. La complexité génétique de $\mathrm{HSV}-1$, la gamme de possibilités offertes tant au niveau du type de vecteur que du type de mutant, ainsi que les différents modes d'interaction que ce virus peut établir avec les cellules, donnent à ce système de vecteurs une souplesse particulière, et permet à l'expérimentateur de choisir la construction la plus apte à la réalisation d'un objectif précis. Les vecteurs herpétiques pourront éventuellement être utilisés dans le cadre des programmes de thérapie génique, au moins chez l'animal et peut-être aussi chez l'homme, mais à condition de mieux comprendre et maîtriser les mécanismes régissant l'établissement, le maintien et la réactivation de l'infection latente dans les cellules nerveuses et de résoudre deux problèmes majeurs : d'une part, l'élimination complète de toute action toxique pour les cellules infectées et pour l'organisme en général, et, d'autre part, l'obtention d'une expression du transgène qui soit en même temps stable, spécifique et soumise aux mêmes contrôles que le gène devant être remplacé. Beaucoup de travail reste donc à accomplir, mais au rythme actuel des progrès de la génétique moléculaire, nous ne serions pas surpris de voir, dans un avenir proche, les virus herpès s'ajouter à la panoplie de vecteurs viraux utilisables en thérapie génique

\section{Summary}

Herpesvirus vectors for gene transfer

Vectors derived from herpes simplex virus, either virus-derived (recombinant virus) or plasmid-derived (amplicons) provide a means of gene delivery to mammalian postmitotic cells. They are being employed : (a) to explore neural networks; (b) to define and to evaluate the state of neuronal promoter elements ; (c) to alter cellular physiology by inducing the expression of a modified protein or of a protein that is normally absent in a particular cell type ; and (d) to effect gene replacement, either in vitro or in vivo. HSV-1 vectors will probably also prove useful for other cell types. However, further progress in the understanding of viral pathogenesis, in the suppression of viral toxicity and in the control of the expression of the delivered gene is still required, before these vectors could be safely employed in human gene therapy protocols.

\section{TIRÉS A PART}

A. Epstein. 